Article

\title{
Screen-Printed Soft-Nitrided Carbon Electrodes for Detection of Hydrogen Peroxide
}

\author{
Chidiebere I. Ogbu ${ }^{1}$, Xu Feng ${ }^{2}{ }^{\mathbb{D}}$, Samson N. Dada ${ }^{1}$ and Gregory W. Bishop ${ }^{1, *}$ \\ 1 Department of Chemistry, East Tennessee State University, Johnson City, TN 37614, USA \\ 2 Surface Analysis Laboratory, Department of Chemistry, Virginia Polytechnic Institute and State University, \\ Blacksburg, VA 24061, USA \\ * Correspondence: bishopgw@etsu.edu; Tel.: +1-423-439-6914
}

Received: 30 July 2019; Accepted: 26 August 2019; Published: 29 August 2019

updates

\begin{abstract}
Nitrogen-doped carbon materials have garnered much interest due to their electrocatalytic activity towards important reactions such as the reduction of hydrogen peroxide. $\mathrm{N}$-doped carbon materials are typically prepared and deposited on solid conductive supports, which can sometimes involve time-consuming, complex, and/or costly procedures. Here, nitrogen-doped screen-printed carbon electrodes (N-SPCEs) were fabricated directly from a lab-formulated ink composed of graphite that was modified with surface nitrogen groups by a simple soft nitriding technique. N-SPCEs prepared from inexpensive starting materials (graphite powder and urea) demonstrated good electrocatalytic activity towards hydrogen peroxide reduction. Amperometric detection of $\mathrm{H}_{2} \mathrm{O}_{2}$ using N-SPCEs with an applied potential of $-0.4 \mathrm{~V}$ (vs. $\mathrm{Ag} / \mathrm{AgCl}$ ) exhibited good reproducibility and stability as well as a reasonable limit of detection $(2.5 \mu \mathrm{M})$ and wide linear range (0.020 to $5.3 \mathrm{mM})$.
\end{abstract}

Keywords: screen-printed electrode; amperometric sensor; nitrogen-doped carbon; soft nitriding

\section{Introduction}

Over the past few decades, screen-printed carbon electrodes (SPCEs) have emerged as important analytical devices, especially for sensing and biosensing, due to their relatively low cost, ease of fabrication, versatility, and wide commercial availability [1-3]. However, the use of SPCEs as sensing and biosensing platforms usually requires surface treatment (e.g., mechanical polishing [3], UV-ozone [4], plasma [5], electrochemical activation [6,7], etc.) or modification of the electrode surface with catalysts (e.g., nanomaterials [8-12], enzymes $[1,13,14]$, etc.) in order to impart adequate sensitivity and/or selectivity for electrochemical measurement of the analyte. For example, hydrogen peroxide, an important compound involved in many enzymatic reactions, including as a product of the oxidation of glucose by glucose oxidase [15], has been detected using SPCEs modified with platinum nanoparticles [8,12], carbon-based nanomaterials [9,11], various nanocomposites [16,17], surfactants [18], Prussian blue [10,19], and enzymes [1,13,14], as well as surface treatment using oxygen plasma [5] and electrochemical activation [7]. While these strategies have facilitated electrochemical measurement of $\mathrm{H}_{2} \mathrm{O}_{2}$ at low limits of detection and with high sensitivity, wider adoption of these techniques outside of the research lab can often be hampered by time-consuming or complex protocols and high costs associated with the required materials and processing equipment.

Recently, nitrogen-doped carbon materials have found increasing use in $\mathrm{H}_{2} \mathrm{O}_{2}$ sensing. $\mathrm{N}$-doped carbon materials can be produced from various methods such as pyrolysis of iron(II) phthalocyanine $[20,21]$ or pyridine/ferrocene mixtures [22,23], nitrogen plasma treatment of graphene [24,25] or carbon nanofibers [26], hydrothermal treatment of carbon nanofiber powder with urea [26], thermal annealing of graphene oxide with ammonia [27], and heating carbon nanotubes or graphene nanoribbons in the presence of ammonium hydroxide [11]. The doping 
of nitrogen atoms into graphitic structures introduces free electrons and facilitates $\mathrm{O}-\mathrm{O}$ bond breakage at these electrocatalytically active sites [11]. Since many strategies for preparing N-doped carbon materials and nanomaterials that are commonly used in $\mathrm{N}$-doping processes (e.g., carbon nanotubes, graphene oxide, etc.) involve metal-containing precursors (e.g., iron(II) phthalocyanine) or oxidizing agents (e.g., permanganate), the possible presence of metal impurities and their effects on electrocatalytic performance of $\mathrm{N}$-doped carbon materials have also been scrutinized [28-32]. For N-doped carbon preparation strategies involving metals, great efforts have been made to demonstrate complete removal of metal impurities $[21,28]$ or document their inability to behave electrocatalytically due to their encapsulation within N-doped carbon structures [20]. However, the desire to eliminate the possible introduction of metal impurities and the subsequent need for their removal has spurred much research in the development of metal-free protocols for preparing N-doped carbon materials [28-32].

Recently, Liu et al. reported that nitrogen groups can be introduced onto various carbon blacks, mesoporous carbons, and activated carbons through simple low-temperature annealing with urea (soft nitriding) [33]. Thermolysis of urea is a metal-free process that produces isocyanic acid and ammonia, which are thought to react mostly with oxygenated surface sites on carbon materials, resulting in the incorporation of ureido groups and ketimine functionalities, respectively. While $\mathrm{N}$-doping of carbon materials through soft nitriding was found to enable immobilization of highly electrocatalytically active metal nanoparticles through reduction of metal precursor ions via sodium borohydride $[33,34]$, the electrocatalytic behavior of the soft-nitrided carbon materials themselves towards hydrogen peroxide reduction has not yet been reported.

In these studies, we show that SPCEs prepared from nitrogen-doped graphite (N-SPCEs) are suitable, economical platforms for electrocatalytic reduction of $\mathrm{H}_{2} \mathrm{O}_{2}$. N-SPCEs are produced from low-cost starting materials (graphite and urea) by soft nitriding and the use of screen-printing eliminates the need to distribute N-doped carbon on other solid electrode supports. N-SPCEs are applied for amperometric detection of $\mathrm{H}_{2} \mathrm{O}_{2}$ and exhibit sensitivity, reproducibility, and long-term stability that are comparable to other $\mathrm{H}_{2} \mathrm{O}_{2}$ sensors based on $\mathrm{N}$-doped carbon materials supported on SPCEs or glassy carbon electrodes (GCEs).

\section{Experimental}

\subsection{Materials}

Graphite powder, urea, cellulose acetate, acetone, cyclohexanone, potassium chloride, ferrocenemethanol $(\mathrm{FcMeOH})$, potassium ferricyanide, potassium ferrocyanide, bovine calf serum, 2,2'-Azino-bis (3-ethylbenzothiazoline-6-sulfonic acid) diammonium salt (ABTS), and horseradish peroxidase (HRP, type II, 200 units/mg) were obtained from Sigma-Aldrich. Hydrogen peroxide (30 wt \%), sodium phosphate dibasic and potassium phosphate monobasic were purchased from Acros Organics. Phosphate buffered saline (PBS) tablets were obtained from Fisher Scientific, and perchloric acid $(70 \%)$ was from Fluka. All aqueous solutions were prepared with $18.2 \mathrm{M} \Omega \mathrm{cm}$ ultrapure water obtained by passing deionized water through a Millipore Synergy purifier.

\subsection{Preparation of $N$-Doped Graphite}

Nitrogen doping of graphite was achieved through a previously reported metal-free soft nitriding protocol [33] with slight modification. Graphite powder (1 g) was mixed with solid urea (1.5 g) and annealed in an oven at $150{ }^{\circ} \mathrm{C}$ for two hours followed by $250{ }^{\circ} \mathrm{C}$ for two hours. The product was washed with water and ethanol three times. The resulting $\mathrm{N}$-doped graphite was then collected and dried at $70{ }^{\circ} \mathrm{C}$ before use.

\subsection{Characterization of Carbon Materials}

Scanning electron microscopy (SEM) was performed using an FEI Quanta 600 FEG environmental scanning electron microscope and a Bruker QUANTAX 400 energy dispersive X-ray spectrometer 
(EDS). X-ray photoelectron spectroscopy (XPS) analyses of graphite and N-doped graphite were carried out using a PHI VersaProbe III scanning XPS microscope equipped with a monochromatic $\mathrm{Al} \mathrm{K-} \alpha$ X-ray source $(1486.6 \mathrm{eV})$. Spectra were acquired with $200 \mu \mathrm{m} / 50 \mathrm{~W} / 15 \mathrm{kV}$ X-ray settings and dual-beam charge neutralization. Binding energies were referenced to $\mathrm{sp}^{2}$ carbon peak at $284.3 \mathrm{eV}$. Atomic surface concentrations (\%) of elements were determined from the integrated intensity of the elemental photoemission features corrected by relative atomic sensitivity factors. Fourier-transform infrared spectroscopy (FTIR) was performed using a Shimadzu IRPrestige-21 spectrometer equipped with a Pike MIRacle ATR sampling accessory. Spectra were obtained from the average of 16 scans from 600 to $4000 \mathrm{~cm}^{-1}$ at $4 \mathrm{~cm}^{-1}$ resolution.

\subsection{Preparation of SPCEs and N-SPCES}

Simple conductive inks composed of graphite or $\mathrm{N}$-doped graphite in a cyclohexanone-acetone solvent mixture (1:1 by volume) with cellulose acetate as the polymeric binder were prepared based on previous reports $[35,36]$. Briefly, cellulose acetate $(0.06 \mathrm{~g})$, cyclohexanone $(1 \mathrm{~mL})$, and acetone $(1 \mathrm{~mL})$ were mixed together and sonicated for $20 \mathrm{~min}$ to obtain a homogenous mixture. Then, graphite or $\mathrm{N}$-doped graphite powder $(0.94 \mathrm{~g})$ was added, and the mixture was sonicated for an additional $40 \mathrm{~min}$. SPCE and N-SPCE working electrodes were manually printed onto plastic cellulose acetate sheets using a 110-mesh screen prepared as previously described [37].

\subsection{Electrochemical Measurements}

Cyclic voltammetry (CV) and amperometry were performed using a $\mathrm{CH}$ Instruments 1040C electrochemical analyzer with a SPCE or N-SPCE working electrode, $\mathrm{Ag} / \mathrm{AgCl}(1 \mathrm{M} \mathrm{KCl})$ reference electrode ( $\mathrm{CH}$ Instruments), and a platinum wire counter electrode. All currents were converted to current density by normalizing measured current by the geometric surface area of the working electrode $\left(0.028 \mathrm{~cm}^{2}\right.$ [37]) $[11,26,38,39]$. Chronocoulometry and electrochemical impedance spectroscopy were carried out using a $\mathrm{CH}$ Instruments $760 \mathrm{E}$ electrochemical analyzer. Chronocoulometry of $0.5 \mathrm{mM}$ $\mathrm{FcMeOH}$ in $0.1 \mathrm{M} \mathrm{KCl}$ was performed by stepping the potential of the working electrode (SPCE or $\mathrm{N}$-SPCE) from $0 \mathrm{~V}$ to $100 \mathrm{mV}$ more positive than peak potential associated with oxidation of $\mathrm{FcMeOH}$ to $\mathrm{FcMeOH}^{+}$based on $\mathrm{CV}$ experiments performed at a scan rate of $50 \mathrm{mV} \mathrm{s}^{-1}$. EIS measurements were recorded in $5 \mathrm{mM} \mathrm{Fe}(\mathrm{CN})_{6}{ }^{3-/ 4-}$ in $0.1 \mathrm{M} \mathrm{KCl}$ at the open-circuit potential $(+0.22 \mathrm{~V}$ vs. $\mathrm{Ag} / \mathrm{AgCl})$ using a frequency range of $10 \mathrm{kHz}-0.1 \mathrm{~Hz}$ and AC perturbation amplitude of $5 \mathrm{mV}$. EIS data were fitted to an equivalent circuit model using EIS Analyser Software [40].

\subsection{Spectrophotometric Assay for $\mathrm{H}_{2} \mathrm{O}_{2}$}

A previously reported spectrophotometric $\mathrm{H}_{2} \mathrm{O}_{2}$ assay based on ABTS-HRP [41] was carried out for comparison to electrochemical detection. Briefly, $1 \mathrm{~mL}$ of a solution containing $0.0144 \mathrm{mM}$ ABTS and $0.021 \mathrm{mg} \mathrm{mL}^{-1} \mathrm{HRP}$ was added to a cuvette. Thirty microliters of $\mathrm{H}_{2} \mathrm{O}_{2}$ standard (prepared in $0.1 \mathrm{M} \mathrm{HClO}_{4}$ ) or sample was introduced and quickly mixed in the cuvette containing the ABTS-HRP solution. The absorbance was measured at $414 \mathrm{~nm}$ using a UV-Vis spectrophotometer (Shimadzu UV-1700 Pharmaspec). The reference for UV-Vis measurements consisted of $1 \mathrm{~mL}$ of the ABTS-HRP solution mixed with $30 \mu \mathrm{L}$ of $0.1 \mathrm{M} \mathrm{HClO}_{4}$ as previously described [41].

\section{Results}

\subsection{Characterization of Nitrogen-Doped Graphite}

Soft nitriding did not appear to significantly change the overall surface morphology/structure of graphite particles based on SEM images (Figure 1). However, N-doped graphite particles did seem to have smoother and more rounded edges (Figure 1b) than untreated graphite (Figure 1a). $\mathrm{N}$-doped graphite samples imaged without prior application of an $\mathrm{Au} / \mathrm{Pd}$ coating exhibited areas of intense surface charging (Figure 1c), which were not observed on untreated graphite samples and 
are indicative of the presence of insulating surface atoms such as nitrogen and oxygen. EDS analysis of high surface charging areas confirms the existence of nitrogen and oxygen atoms on the N-doped graphite surface (Figure 1d).
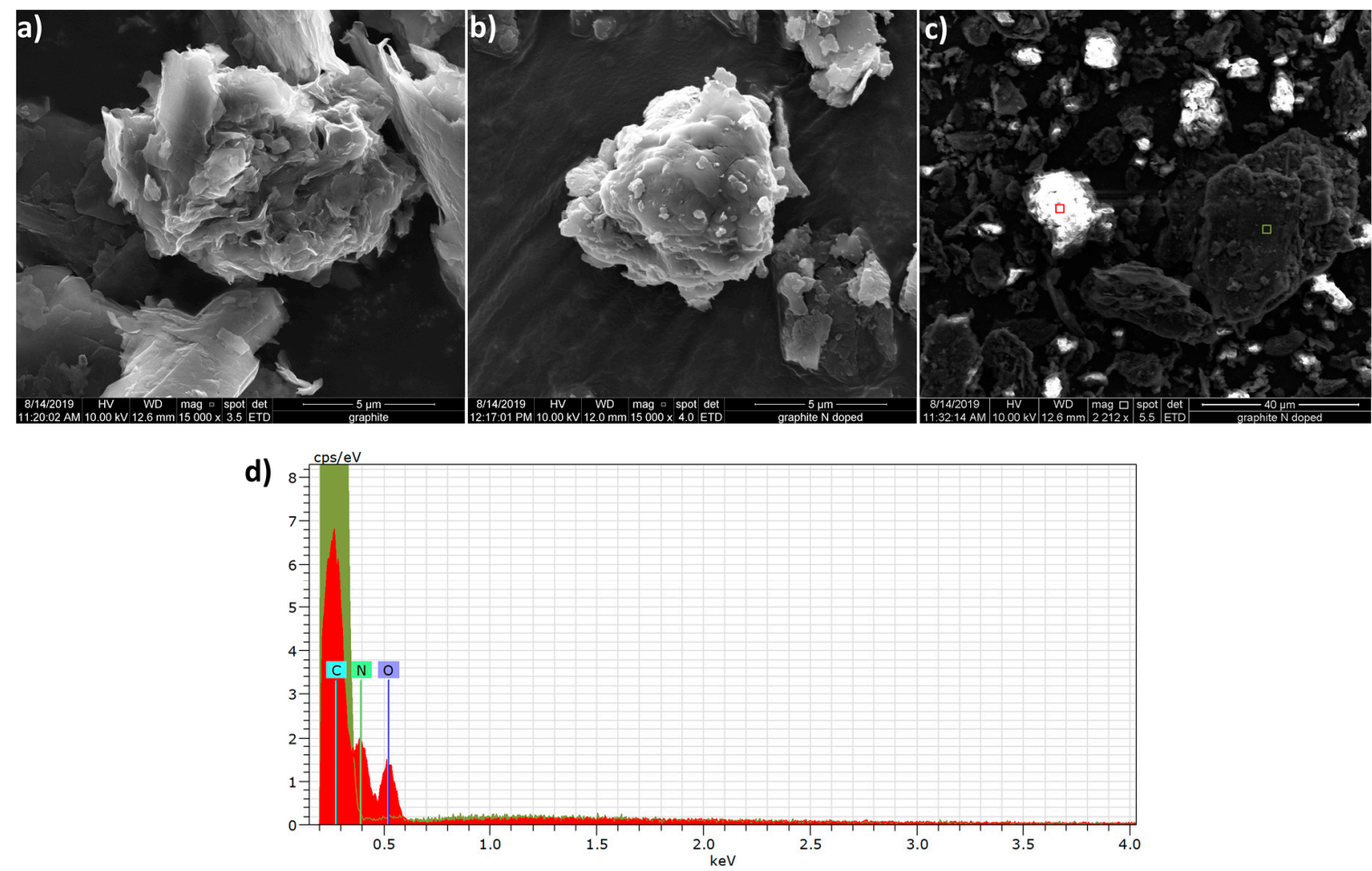

Figure 1. SEM/EDS of graphite and N-doped graphite. SEM images depict untreated (a) and N-doped graphite (b) particles. An SEM image of $\mathrm{N}$-doped graphite obtained without prior application of $\mathrm{Au} / \mathrm{Pd}$ conductive coating (c) exhibits areas of high surface charging (bright spots). Red and green boxes correspond to areas analyzed by EDS. EDS analysis (d) shows the absence of oxygen and nitrogen in an area of low surface charging (green shaded spectrum corresponding to the green box in (c) and the presence of these atoms in an area of high surface charging (red shaded spectrum corresponding to the red box in (c)).

XPS of untreated graphite exhibited the characteristic intense C1s peak at $284.3 \mathrm{eV}$ (Figure 2a,b) corresponding to $\mathrm{sp}^{2}$ carbon atoms and a broad peak at $\sim 291 \mathrm{eV}$ (Figure $2 \mathrm{~b}$ ) consistent with the $\pi-\pi^{*}$ shake-up transition of graphite as expected [42,43]. A very weak O1s peak at $\sim 532 \mathrm{eV}(0.2 \%)$ was also present, presumably from air contamination (Figure 2f). After low-temperature annealing with urea, XPS survey of the resulting N-doped graphite displayed the notable addition of N1s and O1s signals (Figure 2a). Relative atomic surface concentrations for nitrogen (32.9\%) and oxygen (19.1\%) on N-doped graphite indicate that a significant amount of nitrogen/oxygen-containing groups are introduced on the graphite surface by soft nitriding.

Thermolysis of urea is known to produce isocyanic acid and ammonia, which reportedly introduce ureido groups and n-doping on graphitic layers, respectively, primarily at oxygen-containing sites of carbon materials [33]. However, graphite contains a much lower proportion of such sites-only $0.2 \%$ relative surface atomic $\mathrm{O}$ concentration was measured by XPS in this work (Figure 2a,f)—compared to Printex G carbon black (16\% relative surface atomic O concentration according to a previous study [33]). Besides isocyanic acid and ammonia, thermal decomposition of urea is known to also lead to the formation of various other products through condensation and polymerization reactions [44-47]. Schaber et al. found that pyrolysis of urea in an open reaction vessel at $250-275{ }^{\circ} \mathrm{C}$ resulted primarily in cyanuric acid, ammelide, and ammeline with small amounts of melamine and biuret [45]. Studies have also shown that urea [48] and 1,3,5-triazines [42,49] (e.g., cyanuric acid, 
ammelide, ammeline, and melamine) can strongly adsorb on graphite and even intercalate between graphene layers. 1,3,5-triazines with $-\mathrm{NH}_{2}$ and $-\mathrm{OH}$ substituents can form highly stable 2D networks and supramolecular aggregates [50-54] and can also interact strongly with graphite surfaces through hydrogen bonding [49].
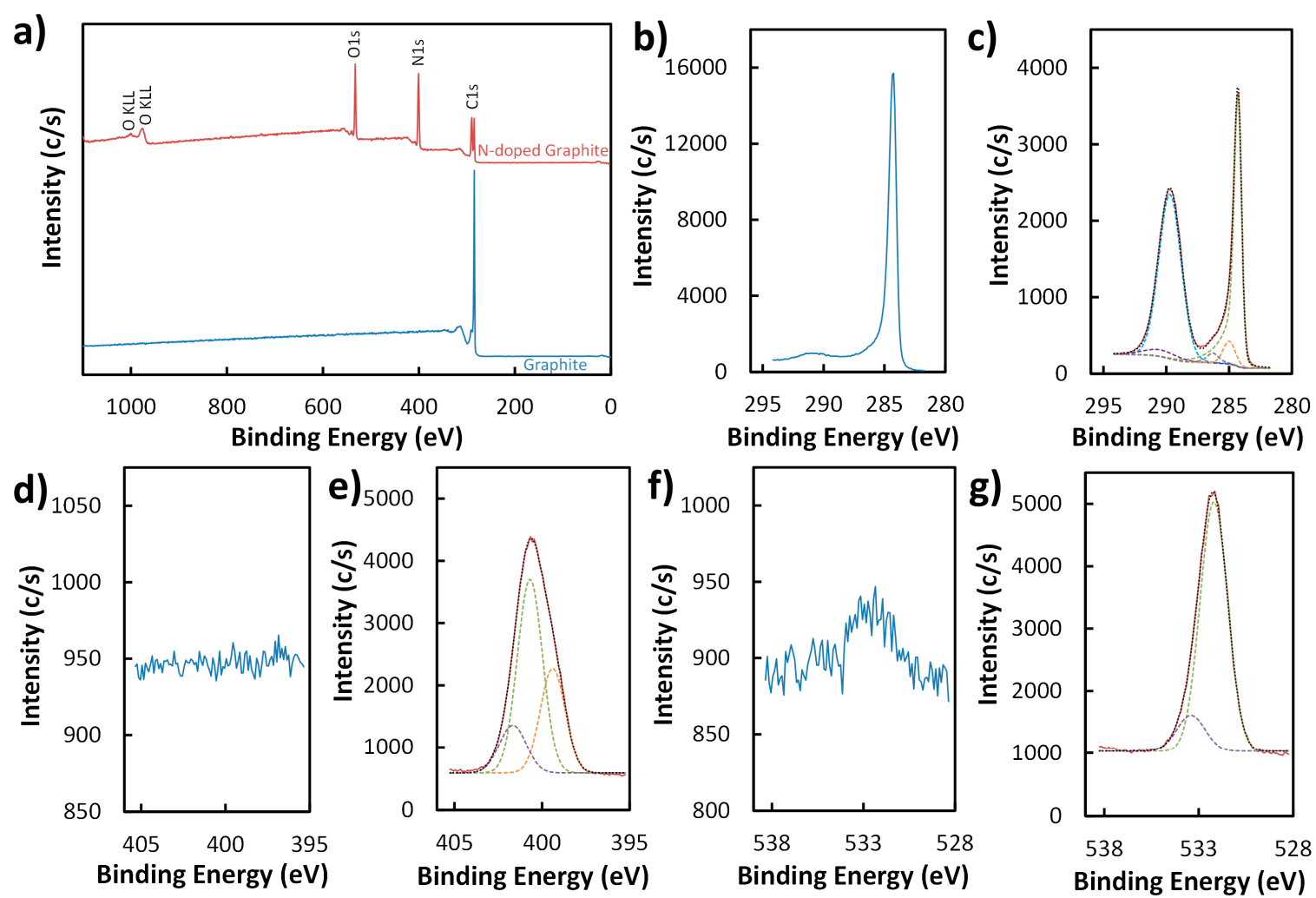

Figure 2. XPS survey (a) and high-resolution (b-g) spectra of graphite (blue) and N-doped graphite (red). High-resolution spectra display the $\mathrm{C} 1 \mathrm{~s}(\mathbf{b}, \mathbf{c}), \mathrm{N} 1 \mathrm{~s}(\mathbf{d}, \mathbf{e})$, and O1s $(\mathbf{f}, \mathbf{g})$ regions for graphite $(\mathbf{b}, \mathbf{d}, \mathbf{f})$ and N-doped graphite (c,e,g). Models (black dotted lines) of C1s (c), N1s (e), and O1s (g) peaks for $\mathrm{N}$-doped graphite (solid red lines) based on deconvolution of the peaks into their major components (green, purple, orange, gray, and light blue dashed lines) are also shown.

The N1s (Figure 2e) and C1s (Figure 2c) features of N-doped graphite appear to support the idea that heating urea in the presence of graphite leads to modification of the carbon surface with 1,3,5-triazines. The N1s feature can be deconvoluted into three peaks (Figure 2e) at $399.4 \mathrm{eV}, 400.7 \mathrm{eV}$, and $401.7 \mathrm{eV}$. The peak at $399.4 \mathrm{eV}$ can be indexed to pyridinic $\mathrm{C}-\mathrm{N}=\mathrm{C}$ of 1,3,5-triazines [52,55]. The largest peak at $400.7 \mathrm{eV}$ is consistent with amide $\mathrm{N}$ of keto tautomers of alcohol-substituted 1,3,5-triazines (i.e., cyanuric acid, ammelide, ammeline) [55]. The trione form of cyanuric acid (isocyanuric acid) is known to be favored [55-57], which helps explain the larger surface atomic concentration of amide $\mathrm{N}(55.6 \%)$ compared to pyridinic $\mathrm{N}(30.7 \%)$. The smallest peak at $401.7 \mathrm{eV}$ corresponds to amine $\mathrm{N}$ atoms in amine-substituted 1,3,5-triazines (i.e., ammelide, ammeline, melamine) [52,55]. In addition to characteristic graphitic carbon signatures, three more peaks at $285.0 \mathrm{eV}, 286.3 \mathrm{eV}$, and $289.7 \mathrm{eV}$ are deconvoluted from the $\mathrm{C} 1 \mathrm{~s}$ feature of the $\mathrm{N}$-doped graphite sample (Figure 2c). The $\mathrm{C} 1 \mathrm{~s}$ peak at $289.7 \mathrm{eV}$ provides additional evidence of surface modification as it is consistent with the presence of $\mathrm{O}=\mathrm{C}-\mathrm{N}$ groups [55]. The minor components at $285.0 \mathrm{eV}$ and $286.3 \mathrm{eV}$ are assigned to $\mathrm{sp}^{3} \mathrm{C}$ atoms [43] and $\mathrm{C}-\mathrm{O}$ or $\mathrm{C}-\mathrm{N}[42,46,58,59]$, respectively. The O1s feature of N-doped graphite can be deconvoluted into two peaks (Figure $2 \mathrm{~g}$ ) at $532.2 \mathrm{eV}$ and $533.4 \mathrm{eV}$, which are attributed to $\mathrm{C}=\mathrm{O}$ and $\mathrm{C}-\mathrm{O}$, respectively.

The FTIR spectrum of $\mathrm{N}$-doped graphite exhibits several bands, which are not observed in the spectrum of untreated graphite, and can be attributed to the presence of 1,3,5-triazine compounds 
(Figure 3). A broad peak centered at $1697 \mathrm{~cm}^{-1}$ in the FTIR spectrum of N-doped graphite (Figure 3b) is consistent with characteristic $\mathrm{C}=\mathrm{O}$ stretching of cyanuric acid [52]. Broad peaks at $3206 \mathrm{~cm}^{-1}$ and $3055 \mathrm{~cm}^{-1}$ are attributed to N-H stretching [60], and strong peaks at $1458 \mathrm{~cm}^{-1}$ and $1416 \mathrm{~cm}^{-1}$ are attributed to stretching modes in C-N heterocycles [61]. The small peak at $1775 \mathrm{~cm}^{-1}$ and peak at $775 \mathrm{~cm}^{-1}$ may indicate hydrogen bonding between 1,3,5-triazines as previous studies found that such interactions encountered during the formation of supramolecular aggregates of cyanuric acid and melamine shifted the $\mathrm{C}=\mathrm{O}$ stretching vibration of cyanuric acid and triazine ring vibration of melamine, respectively, to these regions of the IR spectrum [52,53].
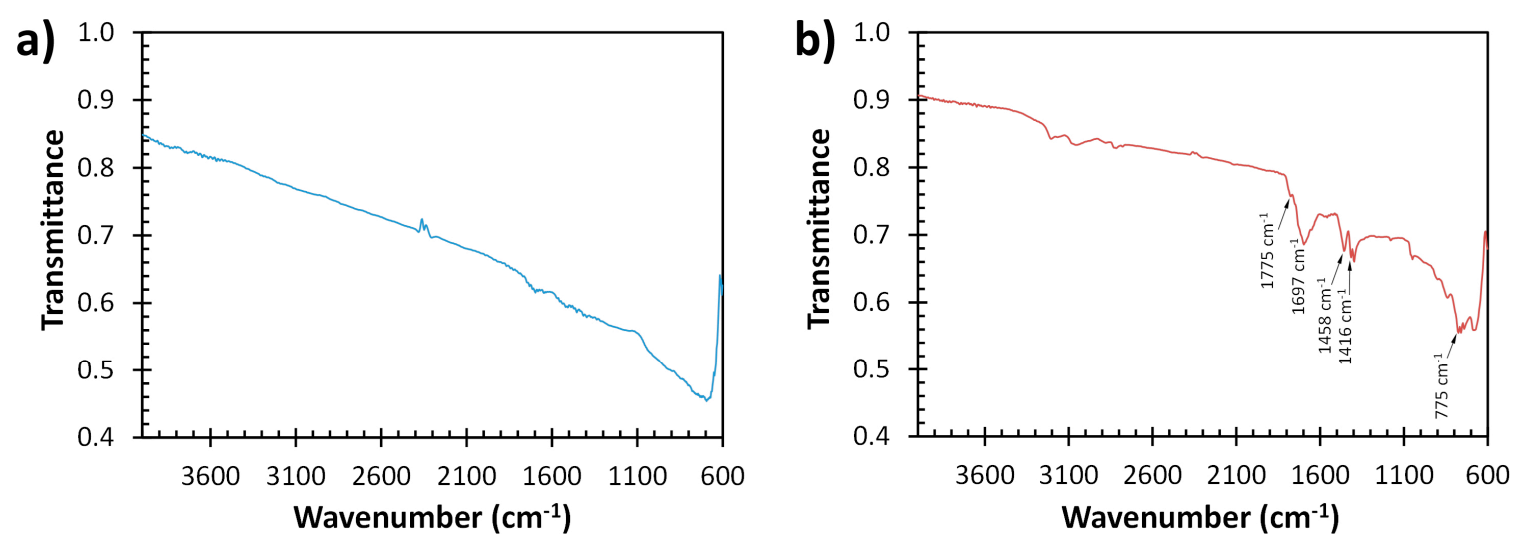

Figure 3. FTIR spectra of graphite (a) and N-doped graphite (b).

\subsection{Electrochemical Characterization and Electrocatalytic Behavior of SPCEs and N-SPCEs}

Electrochemical performance of SPCEs is known to depend on factors like the structural characteristics of carbon (e.g., edge plane-like sites/defects, etc.) used in the ink formulation as well as the ratio and distribution of insulating polymeric and conductive domains in the printed electrode [62-64]. SPCEs and N-SPCEs prepared from graphite- and N-doped graphite-based inks, respectively, exhibited similar electrochemical behavior towards the $\mathrm{FcMeOH} / \mathrm{FcMeOH}{ }^{+}$redox couple in cyclic voltammetry (CV) experiments in terms of peak current density (Figure 4a). However, smaller peak separation ( $109 \mathrm{mV}$ vs. $201 \mathrm{mV}$ with $50 \mathrm{mV} \mathrm{s}^{-1}$ scan rate) and lower charging current were observed using N-SPCEs. Though peak separations $\left(\Delta E_{\mathrm{P}}\right)$ for the $\mathrm{FcMeOH} / \mathrm{FcMeOH}{ }^{+}$redox couple on both SPCEs and N-SPCEs are much larger than the expected Nernstian value of $59 \mathrm{mV}$, the results are comparable to commercially available SPCEs and SPCEs prepared from commercially available inks $[9,37,63]$.

$\Delta E_{\mathrm{P}}$ is known to be related to electron transfer kinetics, and can be used to estimate the heterogeneous electron transfer rate constant $k^{0}$, which often serves as a basis for evaluating the performance of electrode materials $[37,63,65,66]$. For a quasireversible system, $\Delta E_{\mathrm{P}}$ is a function of voltammetric scan rate $(v)$. The link between $\Delta E_{\mathrm{P}}, v$, and $k^{0}$ is made through $\psi$, a dimensionless kinetic parameter introduced by Nicholson $[67,68]$ and related to $\Delta E_{\mathrm{P}}$ (in $\mathrm{mV}$ ) through an empirical equation reported by Lavagnini et al. [69]:

$$
\psi=\left[-0.6288+0.0021\left(\Delta E_{\mathrm{P}}\right)\right] /\left[1-0.017\left(\Delta E_{\mathrm{P}}\right)\right]
$$

The relationship between $\psi$ and $k^{0}$ is given by:

$$
\psi=k^{0}[\pi D n F v /(R T)]^{-1 / 2}
$$

where $D$ is the diffusion coefficient of the electroactive species $\left(D=7.80 \times 10^{-6} \mathrm{~cm}^{2} \mathrm{~s}^{-1}\right.$ [37] for $\mathrm{FcMeOH}), n$ is the number of electrons involved in the Faradaic reaction, $F$ is the Faraday constant, $R$ is the gas constant, and $T$ is temperature. To determine $k^{0}$, Equation (1) is applied to calculate $\psi$ for 
$\Delta E_{\mathrm{P}}$ obtained at different $v$, and $\psi$ is plotted as a function of $v^{-1 / 2}$. The slope of linear plot is related to $k^{0}$ by Equation (2). $\Delta E_{\mathrm{P}}$ values for the $\mathrm{FcMeOH} / \mathrm{FcMeOH}^{+}$redox couple using both SPCEs and N-SPCEs were found to vary with $v$ over the range of 10 to $200 \mathrm{mV} \mathrm{s}^{-1}$, and plots of $\psi$ as a function of $v^{-1 / 2}$ (Figure $4 \mathrm{~b}$ ) displayed excellent linearity $\left(\mathrm{R}^{2}>0.996\right)$. Based on slopes of the linear fits of $\psi$ vs. $v^{-1 / 2}$ and Equation (2), $k^{0}$ values for $\mathrm{FcMeOH} / \mathrm{FcMeOH}{ }^{+}$were found to be $1.56 \times 10^{-3} \mathrm{~cm} \mathrm{~s}^{-1}$ and $3.07 \times 10^{-3} \mathrm{~cm} \mathrm{~s}^{-1}$ with SPCE and N-SPCE, respectively. These results indicate improved electron transfer at N-SPCEs compared to SPCEs by about two-fold, and are in agreement with those reported for other SPCEs using $\mathrm{FcMeOH} / \mathrm{FcMeOH}^{+}$and other common redox probes $[37,63,65]$.
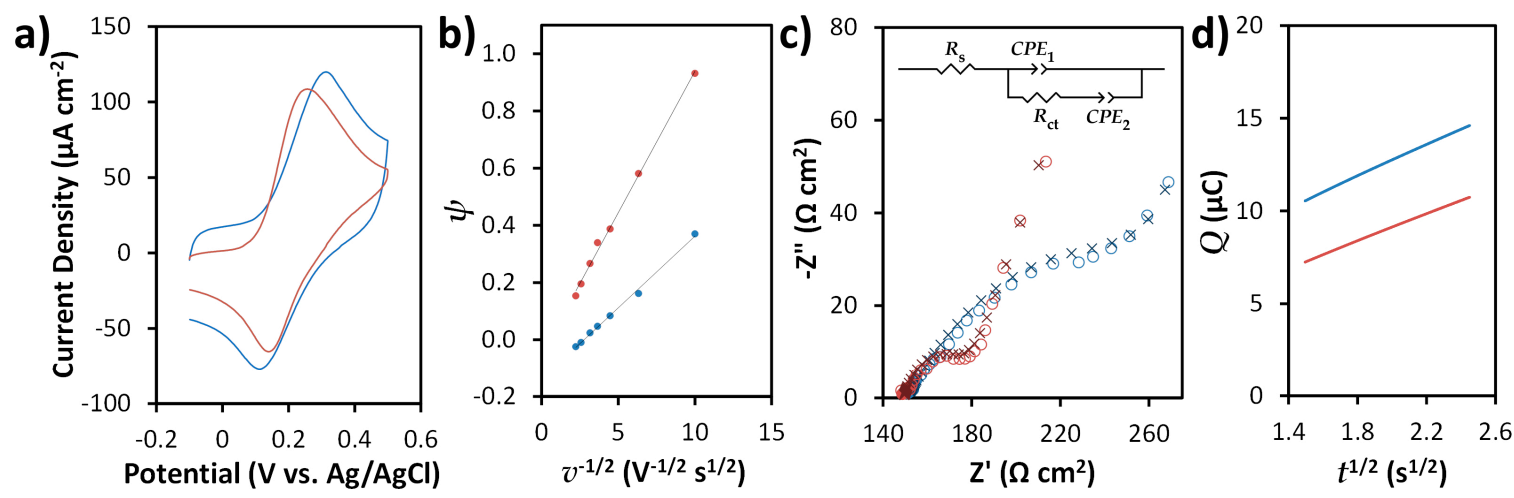

Figure 4. Electrochemical characterization of screen-printed carbon electrodes (SPCEs) (blue) and $\mathrm{N}$-doped screen-printed carbon electrodes (N-SPCEs) (red). (a) Representative CVs for $0.5 \mathrm{mM} \mathrm{FcMeOH}$ with $0.1 \mathrm{M} \mathrm{KCl}$ obtained at a scan rate of $50 \mathrm{mV} \mathrm{s}^{-1}$. (b) Plots for determining heterogeneous electron transfer rate constant $k^{0}$ for the $\mathrm{FcMeOH} / \mathrm{FcMeOH}^{+}$redox reaction based on the relationship between $\Delta E_{\mathrm{P}}$ (expressed in terms of dimensionless kinetic parameter $\psi$ ) and scan rate $v$. (c) Nyquist plots (o) and models of data (x) based on an equivalent circuit (inset) for EIS measurements in $5 \mathrm{mM} \mathrm{Fe}(\mathrm{CN})_{6}{ }^{3-/ 4-}$ in $0.1 \mathrm{M} \mathrm{KCl}$. (d) Anson plot used to determine electroactive surface areas from oxidation of $0.5 \mathrm{mM}$ $\mathrm{FcMeOH}$ in $0.1 \mathrm{M} \mathrm{KCl}$.

Electrochemical performance of SPCEs and N-SPCEs was also characterized by EIS using the $\mathrm{Fe}(\mathrm{CN})_{6}{ }^{3-/ 4-}$ redox system (Figure $4 \mathrm{c}$ ). The experimental data was fitted to an equivalent circuit model (Figure 4c, inset), which was previously utilized by Randviir to model impedance of various redox probe systems, including ascorbic acid (which has been classified by Chen \& McCreery as a probe similar to $\mathrm{Fe}(\mathrm{CN})_{6}{ }^{3-/ 4-}$ due to its sensitivity to carbon electrode surface characteristics [70]) on SPCEs prepared from commercially available inks [66]. $R_{\mathrm{S}}$ represents the resistance of the electrolyte solution [66]. $R_{\mathrm{ct}}$ corresponds to the charge transfer resistance, and $C P E_{1}$ and $C P E_{2}$ are constant phase elements used to model nonideal capacitive behavior due to surface heterogeneity [71]. Compared to SPCE, N-SPCE exhibited lower $R_{\text {ct }}\left(32( \pm 1.2) \Omega \mathrm{cm}^{2}\right.$ vs. $\left.158( \pm 4.2) \Omega \mathrm{cm}^{2}\right)$ for $\mathrm{Fe}(\mathrm{CN})_{6}{ }^{3-/ 4-}$ based on the fitted EIS data, which is indicative of improved electron transfer kinetics and related to $k^{0}$ by $[65,66]$ :

$$
k^{0}=R T /\left(n^{2} F^{2} R_{\mathrm{ct}} A C\right)
$$

where $R, T, n$, and $F$ have the same meanings as in Equation (2), and $A$ and $C$ correspond to the area of the electrode and concentration of the electroactive species, respectively. Based on $R_{\mathrm{ct}}$ determined from EIS and Equation (3), $k^{0}$ for $\mathrm{Fe}(\mathrm{CN})_{6}{ }^{3-/ 4-}$ is $3.33( \pm 0.088) \times 10^{-4} \mathrm{~cm} \mathrm{~s}^{-1}$ using SPCE and $1.67( \pm 0.060) \times 10^{-3} \mathrm{~cm} \mathrm{~s}^{-1}$ using N-SPCE. Previous studies have reported $k^{0}$ for $\mathrm{Fe}(\mathrm{CN})_{6}{ }^{3-/ 4-}$ that range from $1.67 \times 10^{-5} \mathrm{~cm} \mathrm{~s}^{-1}$ to $8.2 \times 10^{-3} \mathrm{~cm} \mathrm{~s}^{-1}$ with commercially available SPCEs and SPCEs prepared from commercially available inks $[6,63,72,73]$. 
The electroactive areas of SPCEs and N-SPCEs were estimated from chronocoulometric measurements according to the Anson equation $[11,74,75]$ :

$$
Q=Q_{d l}+Q_{a d s}+2 n F A_{\mathrm{e}} C(D t / \pi)^{1 / 2}
$$

where $Q_{d l}$ and $Q_{a d s}$ are the charges associated with double-layer charging and Faradaic reactions of adsorbed species, respectively, $A_{\mathrm{e}}$ is electroactive area, $t$ is time, and $n, F, C$, and $D$ have the same meanings as in Equations (2) and (3). Plots of $Q$ vs. $t^{1 / 2}$ (Figure $4 \mathrm{~d}$ ) for the chronocoulometric oxidation of $\mathrm{FcMeOH}$ showed excellent linear behavior in the expected time range [75] with slopes that are related to $A_{\mathrm{e}}$ by Equation 4 . Based on this method, the electroactive areas of SPCEs and N-SPCEs are $0.028( \pm 0.0036) \mathrm{cm}^{2}$ and $0.024( \pm 0.0029) \mathrm{cm}^{2}(n=3)$, respectively, which are consistent with the geometric area $\left(0.028 \mathrm{~cm}^{2}\right)$ of the electrodes.

$\mathrm{CV}$ experiments were carried out in the absence and presence of $20 \mathrm{mM} \mathrm{H}_{2} \mathrm{O}_{2}$ in $0.05 \mathrm{M}$ phosphate buffer ( $\mathrm{pH}$ 7.4) in order to evaluate reduction of $\mathrm{H}_{2} \mathrm{O}_{2}$ on SPCEs and N-SPCEs (Figure 5). Compared to SPCEs (Figure 5a), N-SPCEs exhibited a positive shift in potential for the onset of the $\mathrm{H}_{2} \mathrm{O}_{2}$ reduction reaction by $\sim 150 \mathrm{mV}$ and an increase in reduction current density at potentials more negative than $-0.2 \mathrm{~V}$ (Figure $5 \mathrm{~b}$ ), indicative of electrocatalytic behavior of N-SPCEs towards $\mathrm{H}_{2} \mathrm{O}_{2}$ reduction.
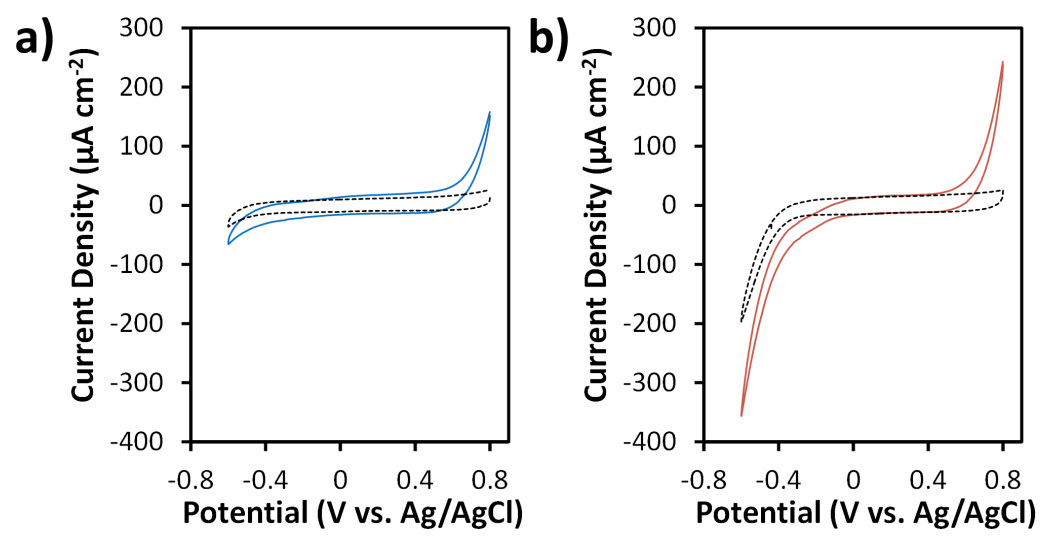

Figure 5. CVs of SPCE (a) and N-SPCE (b) in the absence (dashed lines) and presence (solid lines) of $20 \mathrm{mM} \mathrm{H}_{2} \mathrm{O}_{2}$ in $0.05 \mathrm{M}$ phosphate buffer (pH 7.4). All CVs were obtained at a scan rate of $50 \mathrm{mV} \mathrm{s}^{-1}$.

\subsection{Amperometric Detection of $\mathrm{H}_{2} \mathrm{O}_{2}$ Using N-SPCEs}

Amperometric responses of both SPCEs and N-SPCEs towards $\mathrm{H}_{2} \mathrm{O}_{2}$ using an applied potential of $-0.4 \mathrm{~V}$ were evaluated by successively injecting varying concentrations of $\mathrm{H}_{2} \mathrm{O}_{2}$ into a stirred solution of $0.05 \mathrm{M}$ phosphate buffer (pH 7.4) (Figure 6). SPCEs showed no significant change in measured current density upon addition of $\mathrm{H}_{2} \mathrm{O}_{2}$, whereas N-SPCEs exhibited a rapid increase in reduction current density, reaching steady-state in $<10 \mathrm{~s}$ when $\mathrm{H}_{2} \mathrm{O}_{2}$ was injected into the solution. The relationship between current density and concentration for $\mathrm{H}_{2} \mathrm{O}_{2}$ sensing using N-SPCEs showed excellent linearity $\left(\mathrm{R}^{2}=0.9995\right)$ and good reproducibility $(<5.5 \%$ relative standard deviation for average responses of four different N-SPCEs) in the range of 0.02 to $5.3 \mathrm{mM} \mathrm{H}_{2} \mathrm{O}_{2}$ (Figure $6 \mathrm{~b}$ ). The sensitivity of N-SPCE sensors for $\mathrm{H}_{2} \mathrm{O}_{2}$ was found to be $264( \pm 5.3) \mu \mathrm{A} \mathrm{mM}^{-1} \mathrm{~cm}^{-2}$ based on the slopes of calibration curves for four different N-SPCEs. The limit of detection (LOD) calculated based on three times the standard deviation of the background signal was $2.5 \mu \mathrm{M}$. Sensor stability was evaluated by making repeated measurements of $1 \mathrm{mM} \mathrm{H}_{2} \mathrm{O}_{2}$ using a N-SPCE over a period of 14 days, while storing the N-SPCE at room temperature between measurements. The N-SPCE retained $98 \%$ of its initial response towards $\mathrm{H}_{2} \mathrm{O}_{2}$ reduction after two days, $92 \%$ after one week, and $89 \%$ after two weeks, which is comparable to the reported durability of other $\mathrm{H}_{2} \mathrm{O}_{2}$ sensors based on $\mathrm{N}$-doped carbon materials [11,76]. 

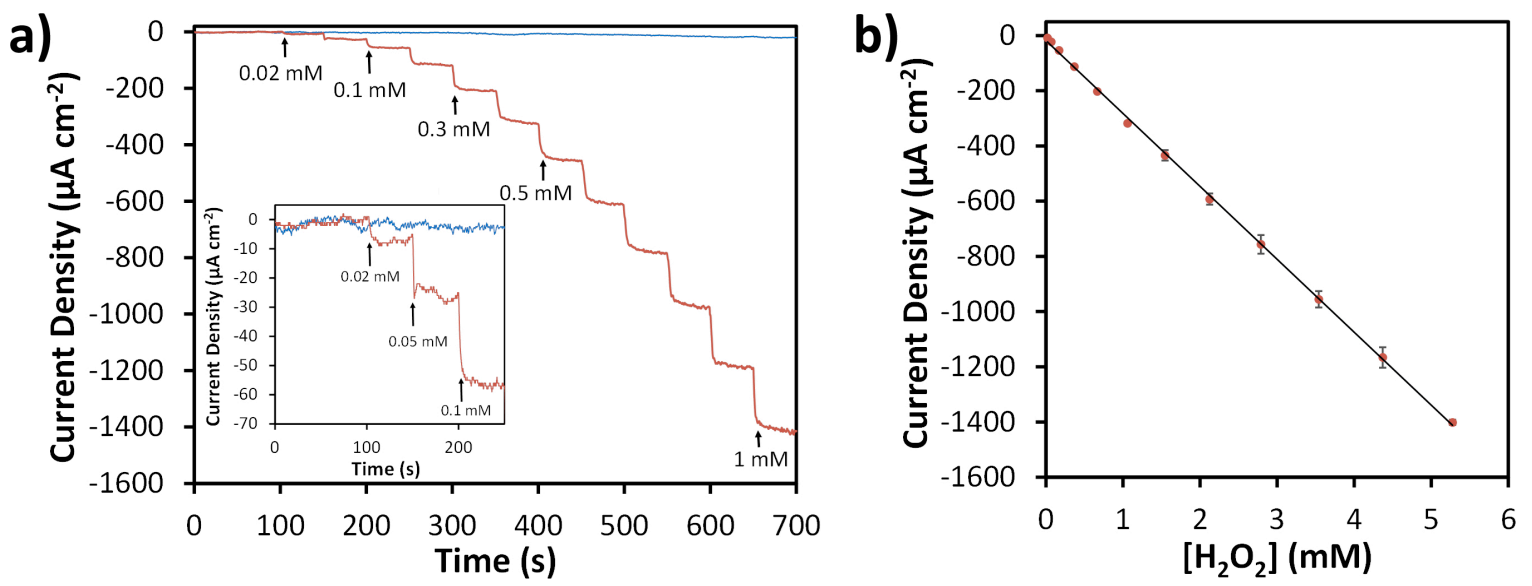

Figure 6. Amperometric detection of $\mathrm{H}_{2} \mathrm{O}_{2}$ in $0.05 \mathrm{M}$ phosphate buffer (pH 7.4) at $-0.4 \mathrm{~V}$ vs. $\mathrm{Ag} / \mathrm{AgCl}$. Representative current-time traces obtained from consecutive injections of $\mathrm{H}_{2} \mathrm{O}_{2}$ (a) using SPCE (blue) and N-SPCE (red). Arrows and labels indicate spike times and concentrations. Inset shows low concentration injections. Calibration curve (b) obtained from average results of four N-SPCEs. Error bars correspond to \pm 1 standard deviation.

Selectivity of the N-SPCE for $\mathrm{H}_{2} \mathrm{O}_{2}$ detection was evaluated by measuring amperometric responses towards species commonly reported to interfere with detection of $\mathrm{H}_{2} \mathrm{O}_{2}$ (e.g., uric acid (UA), dopamine (DA), glucose (Glu), ascorbic acid (AA) $[11,26,38,39,77,78]$ ) (Figure 7). At an applied potential of $-0.4 \mathrm{~V}$ vs. $\mathrm{Ag} / \mathrm{AgCl}$, the N-SPCE showed no significant response towards UA, DA, Glu, or AA when these species were spiked into $0.05 \mathrm{M}$ phosphate buffer ( $\mathrm{pH}$ 7.4) to concentrations of $0.1 \mathrm{mM}$. Performance of the N-SPCE-based $\mathrm{H}_{2} \mathrm{O}_{2}$ sensor in a complex matrix was assessed through measurement of $\mathrm{H}_{2} \mathrm{O}_{2}$ in bovine calf serum, which has been reported to be a suitable and convenient alternative to human serum for use in the development electrochemical biosensors [79]. Bovine serum was mixed with $\mathrm{H}_{2} \mathrm{O}_{2}$, and 6 to $500 \mu \mathrm{L}$ of the mixture was injected into $20 \mathrm{~mL}$ of $0.05 \mathrm{M}$ phosphate buffer so that the spiked $\mathrm{H}_{2} \mathrm{O}_{2}$ concentration could be determined based on the response measured at the N-SPCE using an applied potential of $-0.4 \mathrm{~V}$. Measured concentrations were in good agreement with those obtained separately by a previously reported spectrometric assay based on the ABTS-HRP system [41] (Table 1). However, amperometric detection of $\mathrm{H}_{2} \mathrm{O}_{2}$ using N-SPCEs offers a simpler procedure and larger linear range, whereas spectrometric analysis of spiked samples containing higher concentrations required prior dilution due to the more limited linear range of the method (10 to $200 \mu \mathrm{M}$ ). Average recoveries for amperometric detection of $\mathrm{H}_{2} \mathrm{O}_{2}$ using N-SPCEs ranged from 91 to $100 \%$ for spike concentrations of 0.015 to $2.50 \mathrm{mM}$. These results are comparable to those obtained from similar experiments for detection of $\mathrm{H}_{2} \mathrm{O}_{2}$ in the presence of dilute human serum using SPCEs modified with a reduced graphene oxide-persimmon tannin-platinum nanoparticle composite [17] and GCEs modified with nitrogen-doped carbon nanoparticles embedded in a carbon nanofiber film [38].

Table 1. Spike recoveries for $\mathrm{H}_{2} \mathrm{O}_{2}$ in bovine calf serum measured using N-SPCE at $-0.4 \mathrm{~V}$ in $0.05 \mathrm{M}$ phosphate buffer (pH 7.4) and comparison of amperometric detection to an ABTS-HRP-based assay for $\mathrm{H}_{2} \mathrm{O}_{2}$ [41]. Results are presented as average ( \pm 1 standard deviation) $(n=3)$.

\begin{tabular}{cccc}
\hline Spiked $(\mathbf{m M})$ & Measured $(\mathbf{m M})$ & \% Recovery & ABTS-HRP Assay $(\mathbf{m M})$ \\
\hline 0.015 & $0.0137( \pm 0.00019)$ & $91( \pm 1.3)$ & $0.016( \pm 0.0011)$ \\
0.025 & $0.024( \pm 0.0010)$ & $97( \pm 4.0)$ & $0.024( \pm 0.0012)$ \\
0.080 & $0.074( \pm 0.0021)$ & $93( \pm 2.7)$ & $0.080( \pm 0.0012)$ \\
0.40 & $0.39( \pm 0.026)$ & $98( \pm 6.5)$ & $0.39( \pm 0.012)$ \\
2.50 & $2.49( \pm 0.062)$ & $100( \pm 2.5)$ & $2.41( \pm 0.040)$ \\
\hline
\end{tabular}




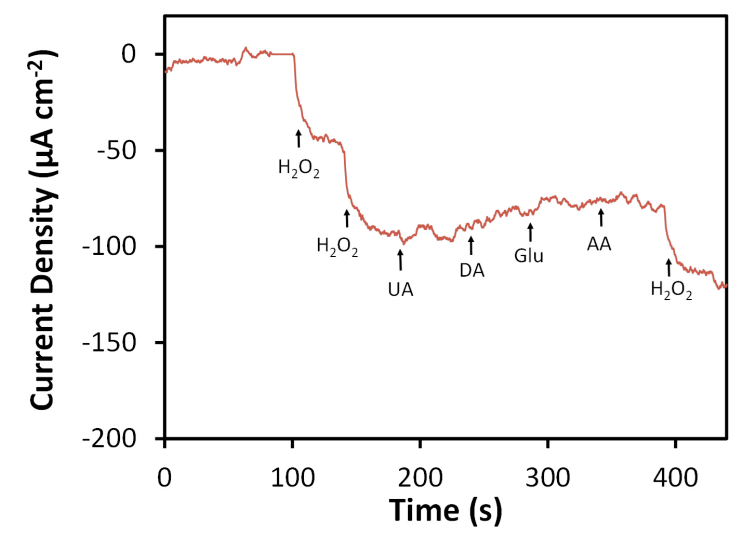

Figure 7. Amperometric response of N-SPCE towards $\mathrm{H}_{2} \mathrm{O}_{2}$ and common interfering species in $0.05 \mathrm{M}$ phosphate buffer ( $\mathrm{pH} 7.4$ ) at $-0.4 \mathrm{~V}$ vs. $\mathrm{Ag} / \mathrm{AgCl}$. Arrows and labels indicate injection times and species. Spiked concentrations for $\mathrm{H}_{2} \mathrm{O}_{2}$, uric acid (UA), dopamine (DA), glucose (Glu), and ascorbic acid (AA) were $0.1 \mathrm{mM}$ for each injection.

\section{Discussion}

Low-temperature annealing of carbon blacks, activated carbons, and mesoporous carbons with urea was recently reported as a method for introducing nitrogen groups (soft nitriding) onto the surfaces of these materials [33]. Nitrogen atoms are believed to be incorporated primarily through reactions of isocyanic acid and ammonia with oxygenated surface sites. Based on the apparent importance of surface oxygen species, the lack of oxygen-containing sites would seem to impede the success of soft nitriding of graphite. However, in studies presented here, annealing of graphite with urea at $250{ }^{\circ} \mathrm{C}$ similarly introduced nitrogen groups, with XPS and FTIR indicating the presence of pyridinic, amide, and amine $\mathrm{N}$ as well as $\mathrm{CN}$ heterocycles consistent with formation of 1,3,5-triazines. 1,3,5-triazines are known to result from the thermal decomposition of urea [44-47], interact strongly with graphene layers through hydrogen bonding [42], and form supramolecular aggregates [50-54]. Application of a temperature high enough to produce 1,3,5-triazines from urea but low enough to avoid sublimation/decomposition of these compounds, which reportedly begins at temperatures $>250{ }^{\circ} \mathrm{C}$ [45], is likely crucial to achieve successful modification as graphite contains few surface oxygenated species. A previous study reported that thermal annealing of graphite in the presence of urea at $600{ }^{\circ} \mathrm{C}$ resulted in a surface atomic $\mathrm{N}$ concentration of only $1.11 \%$ by XPS [80], while we found annealing at $250{ }^{\circ} \mathrm{C}$ led to $32.9 \%$. A relatively large percentage (30.7\%) of these $\mathrm{N}$ atoms were indexed to pyridinic $\mathrm{N}$, which have been linked to electrocatalytic activity towards $\mathrm{H}_{2} \mathrm{O}_{2}$ reduction $[31,32,39,78,80]$.

Graphite-like conjugated aromatic $\mathrm{CN}$ supramolecular assemblies are known to develop from polycondensation of 1,3,5-triazines formed upon heating urea and can even lead to production graphitic carbon nitride $\left(\mathrm{g}-\mathrm{C}_{3} \mathrm{~N}_{4}\right)$ if urea is heated to a temperature of $450-550{ }^{\circ} \mathrm{C}$ [46]. Though polycondensation of 1,3,5-triazines directly from thermal treatment of urea reportedly requires temperatures of $400{ }^{\circ} \mathrm{C}$ or higher [46], a previous study showed that polycondensation of melamine and cyanuric acid produced directly from urea can proceed at temperatures as low as $250^{\circ} \mathrm{C}$ when urea is heated in the presence of tetraethylorthosilicate [47]. Thermal annealing of graphite with urea at $250^{\circ} \mathrm{C}$ may have also produced some graphite-like conjugated aromatic $\mathrm{CN}$ supramolecular assemblies of 1,3,5-triazines in these studies, which could help explain the large surface nitrogen content found in N-doped graphite by XPS despite the lack of oxygen-containing surface sites in the graphite starting material. While there are several methods to introduce oxygenated surface sites on graphite, these involve additional processing and purification steps, may require additional equipment or instrumentation, and can sometimes introduce impurities that can affect electrocatalytic properties [32].

$\mathrm{N}$-SPCEs prepared from $\mathrm{N}$-doped graphite ink were not significantly different from SPCEs in terms of electroactive area. However, they did exhibit a lower $R_{\mathrm{ct}}$ for $\mathrm{Fe}(\mathrm{CN})_{6}{ }^{3-/ 4-}$ and a larger $k^{0}$ for $\mathrm{FcMeOH} / \mathrm{FcMeOH}^{+}$than SPCEs, which are indicative of improved electrochemical performance. 
Enhancement of electron transfer kinetics by incorporation of nitrogen in carbon materials was previously documented in comparative studies of amorphous carbon thin film electrodes $(\mathrm{a}-\mathrm{C})$ and nitrogenated a-C (a-C:N) [81-83]. Yang et al. found that $k^{0}$ for the $\mathrm{Fe}(\mathrm{CN})_{6}{ }^{3-/ 4-}$ redox probe system increased from $5 \times 10^{-3} \mathrm{~cm} \mathrm{~s}^{-1}$ to $1.5 \times 10^{-2} \mathrm{~cm} \mathrm{~s}^{-1}$ with increasing flow rate $(0-50 \mathrm{sccm})$ of $\mathrm{N}_{2}$ used during preparation of a-C and a-C: $\mathrm{N}$ via pulsed laser-arc deposition of carbon [81]. The reason activity towards $\mathrm{Fe}(\mathrm{CN})_{6}{ }^{3-/ 4-}$ was greater for a-C:N compared to a-C was not clear, but could be the result of higher active site density or differences in double layer structure, which can have large impact on this surface-sensitive inner-sphere redox probe [81]. Behan et al. reported that $R_{\mathrm{ct}}$ for $\mathrm{Ru}(\mathrm{NH})_{6}{ }^{3+/ 2+}$, which like $\mathrm{FcMeOH} / \mathrm{FcMeOH}^{+}$is an outer-sphere redox probe system [75] relatively insensitive to surface microstructure (oxides, adsorbed monolayers, etc.) and largely controlled by electronic properties of the electrode [81-83], decreased by more than ten times using a-C:N (prepared by dc magnetron sputtering in the presence of $5 \% \mathrm{~N}_{2} / \mathrm{Ar}$ gas mixture) when compared to similarly fabricated a-C [83]. The decrease in $R_{\mathrm{ct}}$ was attributed to increased metallic character of a-C:N compared to a-C. In our studies, N-SPCEs showed approximately two times higher $k^{0}$ for $\mathrm{FcMeOH} / \mathrm{FcMeOH}^{+}$and nearly five times lower $R_{\mathrm{ct}}$ for $\mathrm{Fe}(\mathrm{CN})_{6}{ }^{3-/ 4-}$ compared to SPCEs.

N-SPCEs also showed good electrocatalytic behavior towards reduction of $\mathrm{H}_{2} \mathrm{O}_{2}$ with stability and reproducibility that are similar to other electrodes modified with $\mathrm{N}$-doped carbon materials. The sensitivity of N-SPCEs for amperometric detection of $\mathrm{H}_{2} \mathrm{O}_{2}$ was comparable to those of other $\mathrm{N}$-doped carbon-based amperometric sensors, which have been reported as 28.7 to $2180 \mu \mathrm{A} \mathrm{mM}^{-1} \mathrm{~cm}^{-2}$ (Table 2). LODs for $\mathrm{H}_{2} \mathrm{O}_{2}$ using these sensors have also been reported to range from 90 to $0.609 \mu \mathrm{M}$, though values around 2.0 to $1.5 \mu \mathrm{M}$ are most common. While the LOD for $\mathrm{H}_{2} \mathrm{O}_{2}$ obtained with N-SPCEs $(2.5 \mu \mathrm{M})$ is slightly higher than that of most other $\mathrm{N}$-doped carbons, previously reported sensors based on $\mathrm{N}$-doped carbon have all involved immobilization of the materials on solid conductive supports (usually GCEs), whereas N-SPCEs are directly fabricated. Also, other reported N-doping strategies involve more cumbersome processing steps, more expensive starting materials, or additional equipment compared to soft nitriding and screen printing used in the preparation of N-SPCEs. Since soft nitriding of carbon blacks has been shown to enable deposition of highly electrocatalytically active metal nanoparticles on these carbon materials [33], the performance and versatility of N-SPCEs may also be improved by employing a similar method to develop metal nanoparticle-modified N-SPCE sensors.

Table 2. Comparison of some $\mathrm{N}$-doped carbon-based amperometric sensors for $\mathrm{H}_{2} \mathrm{O}_{2}$.

\begin{tabular}{|c|c|c|c|c|c|}
\hline Electrode & $E(V)^{1}$ & Linear Range (mM) & $\begin{array}{c}\text { Sensitivity }{ }^{2} \\
\left(\mu \mathrm{A} \mathrm{mM}^{-1} \mathrm{~cm}^{-2}\right)\end{array}$ & $\operatorname{LOD}(\mu \mathrm{M})$ & Ref. \\
\hline N-Graphene/GCE & -0.2 & $10^{-5}-2.8$ & $\mathrm{NR}^{3}$ & $\mathrm{NR}^{3}$ & {$[24]$} \\
\hline N-GrNR ${ }^{4} / \mathrm{SPCE}$ & -0.4 & $\begin{array}{l}0.005-0.085 \\
0.135-1.385\end{array}$ & $\begin{array}{c}2180 \\
640\end{array}$ & 1.72 & [11] \\
\hline $\begin{array}{c}\mathrm{g}_{-} \mathrm{C}_{3} \mathrm{~N}_{4} \mathrm{NS}^{5} / \mathrm{GCE} \\
\mathrm{N}-\text { Carbon/GCE }\end{array}$ & $\begin{array}{l}-0.3 \\
-0.3\end{array}$ & $\begin{array}{l}0.1-90 \\
0.1-40\end{array}$ & $\begin{array}{l}\mathrm{NR}^{3} \\
\mathrm{NR}^{3}\end{array}$ & $\begin{array}{l}2.0 \\
90\end{array}$ & $\begin{array}{l}{[84]} \\
{[77]}\end{array}$ \\
\hline $\mathrm{N}-\mathrm{CNF}_{\mathrm{ht}}{ }^{6} / \mathrm{GCE}$ & -0.4 & $\begin{array}{l}0.01-0.71 \\
0.71-2.91\end{array}$ & $\begin{array}{l}357 \\
203\end{array}$ & 0.62 & [26] \\
\hline $\mathrm{N}-\mathrm{CNF}_{\mathrm{p}}{ }^{7} / \mathrm{GCE}$ & -0.4 & $\begin{array}{l}0.01-0.21 \\
0.21-2.21\end{array}$ & $\begin{array}{l}257 \\
180\end{array}$ & 1.84 & [26] \\
\hline $\mathrm{OMCN}^{8} / \mathrm{GCE}$ & -0.19 & $\begin{array}{c}0.004-0.04 \\
0.04-12.4\end{array}$ & $\begin{array}{l}642^{9} \\
288^{9}\end{array}$ & 1.52 & [76] \\
\hline N-SEGN ${ }^{10} /$ GCE & -0.4 & $0.01-2.225$ & 231.3 & 0.88 & [39] \\
\hline N-rGO ${ }^{11} / \mathrm{GCE}$ & -0.4 & $0.01-4.625$ & 57.3 & 0.94 & [39] \\
\hline $\mathrm{N}-\mathrm{CNF}$ mat ${ }^{12}$ & -0.5 & $0.5-2.5$ & $28.7^{9}$ & 0.609 & [78] \\
\hline N-CNPF ${ }^{13} / \mathrm{GCE}$ & -0.4 & $0.005-27$ & 383.9 & 1.5 & [38] \\
\hline N-SPCE & -0.4 & $0.02-5.3$ & 264 & 2.5 & This work \\
\hline
\end{tabular}

1 working electrode potential vs. $\mathrm{Ag} / \mathrm{AgCl}$ reference, ${ }^{2}$ based on geometric area of the working electrode, ${ }^{3}$ not reported, ${ }^{4}$ graphene nanoribbon, ${ }^{5}$ graphitic carbon nitride nanosheet, ${ }^{6}$ carbon nanofiber (hydrothermally $\mathrm{N}$-doped), ${ }^{7}$ carbon nanofiber (plasma N-doped), ${ }^{8}$ ordered mesoporous carbon nitride, ${ }^{9}$ based on sensitivity in $\mathrm{mA}$ $\mathrm{mM}^{-1}$ and geometric area reported in reference, ${ }^{10}$ sonoelectrochemical graphene nanosheet, ${ }^{11}$ reduced graphene oxide, ${ }^{12}$ carbon nanofiber mat (polyacrylonitrile fiber embedded with carbon nanotubes), ${ }^{13}$ carbon nanoparticles embedded in carbon nanofiber film. 


\section{Conclusions}

N-SPCEs were prepared from N-doped graphite produced by simple, low-temperature annealing of graphite with urea (soft nitriding). The lack of oxygen-containing sites would seem to be impede the success of soft nitriding of graphite based on a previous report that found surface oxygen species to be the primary sites for introduction of $\mathrm{N}$ atoms on other carbon materials by soft nitriding. Nitrogen groups on $\mathrm{N}$-doped graphite were identified as originating from $-\mathrm{OH}$ - and $-\mathrm{NH}_{2}$-substituted 1,3,5-triazines, which stand in slight contrast to the ureido and ketimine functionalities reportedly introduced primarily at oxygen-containing sites by soft nitriding of carbon black [33]. However, the formation of $-\mathrm{OH}$ - and $-\mathrm{NH}_{2}$-substituted 1,3,5-triazines during soft nitriding of graphite is consistent with previous reports on the thermal decomposition of urea at low temperatures [44-47]. N-SPCEs exhibited electrocatalytic activity towards the reduction of $\mathrm{H}_{2} \mathrm{O}_{2}$ and appropriate performance as $\mathrm{H}_{2} \mathrm{O}_{2}$ sensing platforms, which had not been previously reported for other $\mathrm{N}$-doped carbons prepared by soft nitriding. The simplicity of the soft nitriding procedure, low-cost of the starting materials, and ease of electrode preparation are appealing attributes of N-SPCEs that make them a worthwhile addition to the growing number of $\mathrm{N}$-doped carbon- and SPCE-based $\mathrm{H}_{2} \mathrm{O}_{2}$ sensing platforms.

Author Contributions: Conceptualization, G.W.B.; Methodology, G.W.B.; Validation, C.I.O.; Formal Analysis, C.I.O., G.W.B. and X.F.; Investigation, C.I.O., X.F. and S.N.D.; Writing-Original Draft Preparation, C.I.O. and G.W.B.; Writing-Review and Editing, G.W.B., C.I.O., X.F. and S.N.D.

Funding: Acknowledgment is made to the Donors of the American Chemical Society Petroleum Research Fund for partial support of this research (XPS and SEM/EDS studies) through grant number 58123-UNI5 (G.W.B.). Financial support of sensing studies was provided by the East Tennessee Foundation Butterfly Fund grant number 23020 (G.W.B.). The Surface Analysis Laboratory in the Department of Chemistry at Virginia Tech is supported by the National Science Foundation under Grant No. CHE-1531834.

Acknowledgments: The authors would like to thank Bay Ballew (East Tennessee State University Department of Chemistry) for assistance with the ABTS-HRP assay and Stephen McCartney (Virginia Tech Nanoscale Characterization and Fabrication Laboratory) for assistance with the SEM/EDS analysis.

Conflicts of Interest: The authors declare no conflict of interest.

\section{References}

1. Tangkuaram, T.; Ponchio, C.; Kangkasomboon, T.; Katikawong, P.; Veerasai, W. Design and Development of a Highly Stable Hydrogen Peroxide Biosensor on Screen Printed Carbon Electrode on Horseradish Peroxidase Bound with Gold Nanoparticles in the Matrix of Chitosan. Biosens. Bioelectron. 2007, 22, 2071-2078. [CrossRef] [PubMed]

2. Metters, J.P.; Kadara, R.O.; Banks, C.E. New Directions in Screen Printed Electroanalytical Sensors: An Overview of Recent Developments. Analyst 2011, 136, 1067-1076. [CrossRef] [PubMed]

3. Cumba, L.R.; Foster, C.W.; Brownson, D.A.C.; Smith, J.P.; Iniesta, J.; Thakur, B.; do Carmo, D.R.; Banks, C.E. Can the Mechanical Activation (Polishing) of Screen-Printed Electrodes Enhance Their Electroanalytical Response? Analyst 2016, 141, 2791-2799. [CrossRef] [PubMed]

4. Wang, J.; Xu, Z.; Zhang, M.; Liu, J.; Zou, H.; Wang, L. Improvement of Electrochemical Performance of Screen-Printed Carbon Electrodes by UV/Ozone Modification. Talanta 2019, 192, 40-45. [CrossRef] [PubMed]

5. Wang, S.C.; Chang, K.S.; Yuan, C.J. Enhancement of Electrochemical Properties of Screen-Printed Carbon Electrodes by Oxygen Plasma Treatment. Electrochim. Acta 2009, 54, 4937-4943. [CrossRef]

6. Wang, J.; Pedrero, M.; Sakslund, H.; Hammerich, O.; Pingarron, J. Electrochemical Activation of Screen-Printed Carbon Strips. Analyst 1996, 121, 345-350. [CrossRef]

7. González-Sánchez, M.I.; Gómez-Monedero, B.; Agrisuelas, J.; Iniesta, J.; Valero, E. Highly Activated Screen-Printed Carbon Electrodes by Electrochemical Treatment with Hydrogen Peroxide. Electrochem. Commun. 2018, 91, 36-40. [CrossRef]

8. Chikae, M.; Idegami, K.; Kerman, K.; Nagatani, N.; Ishikawa, M.; Takamura, Y.; Tamiya, E. Direct Fabrication of Catalytic Metal Nanoparticles onto the Surface of a Screen-Printed Carbon Electrode. Electrochem. Commun. 2006, 8, 1375-1380. [CrossRef] 
9. Fanjul-Bolado, P.; Queipo, P.; Lamas-Ardisana, P.J.; Costa-García, A. Manufacture and Evaluation of Carbon Nanotube Modified Screen-Printed Electrodes as Electrochemical Tools. Talanta 2007, 74, 427-433. [CrossRef]

10. Cinti, S.; Arduini, F.; Moscone, D.; Palleschi, G.; Killard, A.J. Development of a Hydrogen Peroxide Sensor Based on Screen-Printed Electrodes Modified with Inkjet-Printed Prussian Blue Nanoparticles. Sensors 2014, 14, 14222-14234. [CrossRef]

11. Shi, L.; Niu, X.; Liu, T.; Zhao, H.; Lan, M. Electrocatalytic Sensing of Hydrogen Peroxide Using a Screen-Printed Carbon Electrode Modified with Nitrogen-Doped Graphene Nanoribbons. Microchim. Acta 2015, 182, 2485-2493. [CrossRef]

12. Agrisuelas, J.; González-Sánchez, M.I.; Valero, E. Hydrogen Peroxide Sensor Based on In Situ Grown Pt Nanoparticles from Waste Screen-Printed Electrodes. Sens. Actuators B 2017, 249, 499-505. [CrossRef]

13. Ledru, S.; Ruillé, N.; Boujtita, M. One-Step Screen-Printed Electrode Modified in Its Bulk with HRP Based on Direct Electron Transfer for Hydrogen Peroxide Detection in Flow Injection Mode. Biosens. Bioelectron. 2006, 21, 1591-1598. [CrossRef] [PubMed]

14. Teng, Y.J.; Zuo, S.H.; Lan, M.B. Direct Electron Transfer of Horseradish Peroxidase on Porous Structure of Screen-Printed Electrode. Biosens. Bioelectron. 2009, 24, 1353-1357. [CrossRef] [PubMed]

15. Wang, J. Electrochemical Glucose Biosensors. Chem. Rev. 2008, 108, 814-825. [CrossRef]

16. Cinti, S.; Arduini, F.; Vellucci, G.; Cacciotti, I.; Nanni, F.; Moscone, D. Carbon Black Assisted Tailoring of Prussian Blue Nanoparticles to Tune Sensitivity and Detection Limit Towards $\mathrm{H}_{2} \mathrm{O}_{2}$ by Using Screen-Printed Electrode. Electrochem. Commun. 2014, 47, 63-66. [CrossRef]

17. Huang, Y.; Xue, Y.; Zeng, J.; Li, S.; Wang, Z.; Dong, C.; Li, G.; Liang, J.; Zhou, Z. Non-Enzymatic Electrochemical Hydrogen Peroxide Biosensor Based on Reduction Graphene Oxide-Persimmon Tannin-Platinum Nanocomposite. Mater. Sci. Eng. C 2018, 92, 590-598. [CrossRef]

18. Yuan, C.J.; Wang, Y.C.; Reiko, O. Improving the Detection of Hydrogen Peroxide of Screen-Printed Carbon Paste Electrodes by Modifying with Nonionic Surfactants. Anal. Chim. Acta 2009, 653, 71-76. [CrossRef]

19. Ricci, F.; Palleschi, G. Sensor and Biosensor Preparation, Optimisation and Applications of Prussian Blue Modified Electrodes. Biosens. Bioelectron. 2005, 21, 389-407. [CrossRef]

20. Maldonado, S.; Stevenson, K.J. Direct Preparation of Carbon Nanofiber Electrodes via Pyrolysis of Iron (II) Phthalocyanine: Electrocatalytic Aspects for Oxygen Reduction. J. Phys. Chem. B 2004, 108, 11375-11383. [CrossRef]

21. Gong, K.; Du, F.; Xia, Z.; Durstock, M.; Dai, L. Nitrogen-Doped Carbon Nanotube Arrays with High Electrocatalytic Activity for Oxygen Reduction. Science 2009, 323, 760-764. [CrossRef] [PubMed]

22. Maldonado, S.; Stevenson, K.J. Influence of Nitrogen Doping on Oxygen Reduction Electrocatalysis at Carbon Nanofiber Electrodes. J. Phys. Chem. B 2005, 109, 4707-4716. [CrossRef] [PubMed]

23. Sharifi, T.; Hu, G.; Jia, X.; Wågberg, T. Formation of Active Sites for Oxygen Reduction Reactions by Transformation of Nitrogen Functionalities in Nitrogen-Doped Carbon Nanotubes. ACS Nano 2012, 6, 8904-8912. [CrossRef] [PubMed]

24. Shao, Y.; Zhang, S.; Engelhard, M.H.; Li, G.; Shao, G.; Wang, Y.; Liu, J.; Aksay, I.A.; Lin, Y. Nitrogen-Doped Graphene and Its Electrochemical Applications. J. Mater. Chem. 2010, 20, 7491-7496. [CrossRef]

25. Wang, Y.; Shao, Y.; Matson, D.W.; Li, J.; Lin, Y. Nitrogen-Doped Graphene and Its Application in Electrochemical Biosensing. ACS Nano 2010, 4, 1790-1798. [CrossRef] [PubMed]

26. Lyu, Y.P.; Wu, Y.S.; Wang, T.P.; Lee, C.L.; Chung, M.Y.; Lo, C.T. Hydrothermal and Plasma Nitrided Electrospun Carbon Nanofibers for Amperometric Sensing of Hydrogen Peroxide. Microchim. Acta 2018, 185, 371. [CrossRef]

27. Shui, J.; Wang, M.; Du, F.; Dai, L. N-Doped Carbon Nanomaterials Are Durable Catalysts for Oxygen Reduction Reaction in Acidic Fuel Cells. Sci. Adv. 2015, 1, e1400129. [CrossRef]

28. Yu, D.; Zhang, Q.; Dai, L. Highly Efficient Metal-Free Growth of Nitrogen-Doped Single-Walled Carbon Nanotubes on Plasma-Etched Substrates for Oxygen Reduction. J. Am. Chem. Soc. 2010, 132, 15127-15129. [CrossRef]

29. Wiggins-Camacho, J.D.; Stevenson, K.J. Mechanistic Discussion of the Oxygen Reduction Reaction at Nitrogen-Doped Carbon Nanotubes. J. Phys. Chem. C 2011, 115, 20002-20010. [CrossRef]

30. Dai, L.; Chang, D.W.; Baek, J.B.; Lu, W. Carbon Nanomaterials for Advanced Energy Conversion and Storage. Small 2012, 8, 1130-1166. [CrossRef] 
31. Dai, L.; Xue, Y.; Qu, L.; Choi, H.J.; Baek, J.B. Metal-Free Catalysts for Oxygen Reduction Reaction. Chem. Rev. 2015, 115, 4823-4892. [CrossRef] [PubMed]

32. Ambrosi, A.; Chua, C.K.; Latiff, N.M.; Loo, A.H.; Wong, C.H.A.; Eng, A.Y.S.; Bonanni, A.; Pumera, M. Graphene and Its Electrochemistry-An Update. Chem. Soc. Rev. 2016, 45, 2458-2493. [CrossRef] [PubMed]

33. Liu, B.; Yao, H.; Song, W.; Jin, L.; Mosa, I.M.; Rusling, J.F.; Suib, S.L.; He, J. Ligand-Free Noble Metal Nanocluster Catalysts on Carbon Supports via "Soft" Nitriding. J. Am. Chem. Soc. 2016, 138, 4718-4721. [CrossRef] [PubMed]

34. Chang, Z.; Yang, Y.; He, J.; Rusling, J.F. Gold Nanocatalysts Supported on Carbon for Electrocatalytic Oxidation of Organic Molecules Including Guanines in DNA. Dalton Trans. 2018, 47, 14139-14152. [CrossRef] [PubMed]

35. Wring, S.A.; Hart, J.P. Chemically Modified, Screen-Printed Carbon Electrodes. Analyst 1992, 117, $1281-1286$. [CrossRef]

36. Miserere, S.; Ledru, S.; Ruillé, N.; Griveau, S.; Boujtita, M.; Bedioui, F. Biocompatible Carbon-Based Screen-Printed Electrodes for the Electrochemical Detection of Nitric Oxide. Electrochem. Commun. 2006, 8, 238-244. [CrossRef]

37. Bishop, G.W.; Ahiadu, B.K.; Smith, J.L.; Patterson, J.D. Use of Redox Probes for Characterization of Layer-by-Layer Gold Nanoparticle-Modified Screen-Printed Carbon Electrodes. J. Electrochem. Soc. 2017, 164, B23-B28. [CrossRef]

38. Zhang, X.; Liu, D.; Yu, B.; You, T. A Novel Nonenzymatic Hydrogen Peroxide Sensor Based on Electrospun Nitrogen-Doped Carbon Nanoparticles-Embedded Carbon Nanofibers Film. Sens. Actuators B 2016, 224, 103-109. [CrossRef]

39. Wu, Y.S.; Liu, Z.T.; Wang, T.P.; Hsu, S.Y.; Lee, C.L. A Comparison of Nitrogen-Doped Sonoelectrochemical and Chemical Graphene Nanosheets as Hydrogen Peroxide Sensors. Ultrason. Sonochem. 2018, 42, 659-664. [CrossRef]

40. Bondarenko, A.S.; Ragoisha, G.A. Progress in Chemometrics Research; Pomerantsev, A.L., Ed.; Nova Science Publishers: New York, NY, USA, 2005; pp. 89-102. Available online: http://www.abc.chemistry.bsu.by/vi/ analyser/ (accessed on 30 July 2019).

41. Cheng, X.; Challier, L.; Etcheberry, A.; Noël, V.; Perez, H. The ABTS-HRP System as an Alternative Method to RRDE for the Determination of the Selectivity of the Oxygen Reduction Reaction. Int. J. Electrochem. Sci. 2012, 7, 6247-6262.

42. León, V.; Quintana, M.; Herrero, M.A.; Fierro, J.L.G.; de la Hoz, A.; Prato, M.; Vázquez, E. Few-Layer Graphenes from Ball-Milling of Graphite with Melamine. Chem. Commun. 2011, 47, 10936-10938. [CrossRef] [PubMed]

43. Ederer, J.; Janoš, P.; Ecorchard, P.; Tolasz, J.; Štengl, V.; Beneš, H.; Perchacz, M.; Pop-Georgievski, O. Determination of Amino Groups on Functionalized Graphene Oxide for Polyurethane nanomaterials: XPS Quantitation vs. Functional Speciation. RSC Adv. 2017, 7, 12464-12473. [CrossRef]

44. Kinoshita, H. Synthesis of Melamine from Urea, II. Rev. Phys. Chem. Jpn. 1954, 24, 19-27.

45. Schaber, P.M.; Colson, J.; Higgins, S.; Thielen, D.; Anspach, B.; Brauer, J. Thermal Decomposition (Pyrolysis) of Urea in an Open Reaction Vessel. Thermochim. Acta 2004, 424, 131-142. [CrossRef]

46. Liu, J.; Zhang, T.; Wang, Z.; Dawson, G.; Chen, W. Simple Pyrolysis of Urea into Graphitic Carbon Nitride with Recyclable Adsorption and Photocatalytic Activity. J. Mater. Chem. 2011, 21, 14398-14401. [CrossRef]

47. Shi, L.; Liang, L.; Wang, F.; Liu, M.; Chen, K.; Sun, K.; Zhang, N.; Sun, J. Higher Yield Urea-Derived Polymeric Graphitic Carbon Nitride with Mesoporous Structure and Superior Visible-Light-Responsive Activity. ACS Sustain. Chem. Eng. 2015, 3, 3412-3419. [CrossRef]

48. Mahalingam, P.; Loganathan, A.; Selvaraju, M.; Sivakumar, P. Simultaneous Exfoliation and Reduction of Urea Intercalated Graphite Oxide Using Microwave Radiation. Graphene 2015, 3, 40-43. [CrossRef]

49. León, V.; Rodriguez, A.M.; Prieto, P.; Prato, M.; Vázquez, E. Exfoliation of Graphite with Triazine Derivatives under Ball-Milling Conditions: Preparation of Few-Layer Graphene via Selective Noncovalent Interactions. ACS Nano 2014, 8, 563-571. [CrossRef]

50. Wang, Y.; Wei, B.; Wang, Q. Crystal Structure of Melamine Cyanuric Acid Complex (1:1) Trihydrochloride, MCA.3HCl. J. Crystallogr. Spectrosc. Res. 1990, 20, 79-84. [CrossRef]

51. Seto, C.T.; Whitesides, G.M. Self-Assembly Based on the Cyanuric Acid-Melamine Lattice. J. Am. Chem. Soc. 1990, 112, 6409-6411. [CrossRef] 
52. Jun, Y.S.; Lee, E.Z.; Wang, X.; Hong, W.H.; Stucky, G.D.; Thomas, A. From Melamine-Cyanuric Acid Supramolecular Aggregates to Carbon Nitride Hollow Spheres. Adv. Funct. Mater. 2013, 23, 3661-3667. [CrossRef]

53. Jun, Y.S.; Park, J.; Lee, S.U.; Thomas, A.; Hong, W.H.; Stucky, G.D. Three-Dimensional Macroscopic Assemblies of Low-Dimensional Carbon Nitrides for Enhanced Hydrogen Evolution. Angew. Chem. Int. Ed. 2013, 52, 11083-11087. [CrossRef] [PubMed]

54. Roy, B.; Bairi, P.; Nandi, A.K. Supramolecular Assembly of Melamine and Its Derivatives: Nanostructures to Functional Materials. RSC Adv. 2014, 4, 1708-1734. [CrossRef]

55. Guo, H.; Ren, Y.; Chen, Q.; Wang, D.; Liu, Y. Gold Nanoparticles on Cyanuric Acid-Based Support: A Highly Active Catalyst for the Reduction of 4-Nitrophenol in Water. Catal. Commun. 2017, 102, 136-140. [CrossRef]

56. Liang, X.; Pu, X.; Zhou, H.; Wong, N.B.; Tian, A. Keto-Enol Tautomerization of Cyanuric Acid in the Gas Phase and in Water and Methanol. J. Mol. Struct.: THEOCHEM 2007, 816, 125-136. [CrossRef]

57. Pérez-Manríquez, L.; Cabrera, A.; Sansores, L.E.; Salcedo, R. Aromaticity in Cyanuric Acid. J. Mol. Model. 2011, 17, 1311-1315. [CrossRef] [PubMed]

58. Malitesta, C.; Losito, I.; Sabbatini, L.; Zambonin, P.G. New Findings on Polypyrrole Chemical Structure by XPS Coupled to Chemical Derivatization Labelling. J. Electron Spectrosc. Relat. Phenom. 1995, 75, 629-634. [CrossRef]

59. Mao, J.; Peng, T.; Zhang, X.; Li, K.; Ye, L.; Zan, L. Effect of Graphitic Carbon Nitride Microstructures on the Activity and Selectivity of Photocatalytic CO2 Reduction under Visible Light. Catal. Sci. Technol. 2013, 3, 1253-1260. [CrossRef]

60. Newman, R.; Badger, R.M. Infrared Spectra of Cyanuric Acid and Deutero Cyanuric Acid. J. Am. Chem. Soc. 1952, 74, 3545-3548. [CrossRef]

61. Zhou, J.; Yang, Y.; Zhang, C. A Low-Temperature Solid-Phase Method to Synthesize Highly Fluorescent Carbon Nitride Dots with Tunable Emission. Chem. Commun. 2013, 49, 8605-8607. [CrossRef]

62. Wang, J.; Tian, B.; Nascimento, V.B.; Angnes, L. Performance of Screen-Printed Carbon Electrodes Fabricated from Different Carbon Inks. Electrochim. Acta 1998, 43, 3459-3465. [CrossRef]

63. Kadara, R.O.; Jenkinson, N.; Banks, C.E. Characterisation of Commercially Available Electrochemical Sensing Platforms. Sens. Actuators B 2009, 138, 556-562. [CrossRef]

64. Choudry, N.A.; Kampouris, D.K.; Kadara, R.O.; Banks, C.E. Disposable Highly Ordered Pyrolytic Graphite-Like Electrodes: Tailoring the Electrochemical Reactivity of Screen Printed Electrodes. Electrochem. Commun. 2010, 12, 6-9. [CrossRef]

65. Washe, A.P.; Lozano-Sánchez, P.; Bejarano-Nosas, D.; Katakis, I. Facile and Versatile Approaches to Enhancing Electrochemical Performance of Screen Printed Electrodes. Electrochim. Acta 2013, 91, 166-172. [CrossRef]

66. Randviir, E.P. A Cross Examination of Electron Transfer Rate Constants for Carbon Screen-Printed Electrodes using Electrochemical Impedance Spectroscopy and Cyclic Voltammetry. Electrochim. Acta 2018, 286, 179-186. [CrossRef]

67. Nicholson, R.S.; Shain, I. Theory of Stationary Electrode Polarography. Single Scan and Cyclic Methods Applied to Reversible, Irreversible, and Kinetic Systems. Anal. Chem. 1964, 36, 706-723. [CrossRef]

68. Nicholson, R.S. Theory and Application of Cyclic Voltammetry for Measurement of Electrode Reaction Kinetics. Anal. Chem. 1965, 37, 1351-1355. [CrossRef]

69. Lavagnini, I.; Antiochia, R.; Magno, F. An Extended Method for Practical Evaluation of the Standard Rate Constant from Cyclic Voltammetric Data. Electroanalysis 2004, 16, 505-506. [CrossRef]

70. Chen, P.; McCreery, R.L. Control of Electron Transfer Kinetics at Glassy Carbon Electrodes by Specific Surface Modification. Anal. Chem. 1996, 68, 3958-3965. [CrossRef]

71. Bernalte, E.; Marín-Sánchez, C.; Pinilla-Gil, E.; Brett, C.M.A. Characterisation of Screen-Printed Gold and Gold Nanoparticle-Modified Carbon Sensors by Electrochemical Impedance Spectroscopy. J. Electroanal. Chem. 2013, 709, 70-76. [CrossRef]

72. Morrin, A.; Killard, A.J.; Smyth, M.R. Electrochemical Characterization of Commercial and Home-Made Screen-Printed Carbon Electrodes. Anal. Lett. 2003, 36, 2021-2039. [CrossRef]

73. Fanjul-Bolado, P.; Hernández-Santos, D.; Lamas-Ardisana, P.J.; Martín-Pernía, A.; Costa-García, A. Electrochemical Characterization of Screen-Printed and Conventional Carbon Paste Electrodes. Electrochim. Acta 2008, 53, 3635-3642. [CrossRef] 
74. Fragkou, V.; Ge, Y.; Steiner, G.; Freeman, D.; Bartetzko, N.; Turner, A.P.F. Determination of the Real Surface Area of a Screen-Printed Electrode by Chronocoulometry. Int. J. Electrochem. Sci. 2012, 7, 6214-6220.

75. Ferrari, A.G.M.; Foster, C.W.; Kelly, P.J.; Brownson, D.A.C.; Banks, C.E. Determination of the Electrochemical Area of Screen-Printed Electrochemical Sensing Platforms. Biosensors 2018, 8, 53. [CrossRef] [PubMed]

76. Zhang, Y.; Bo, X.; Nsabimana, A.; Luhana, C.; Wang, G.; Wang, H.; Li, M.; Guo, L. Fabrication of 2D Ordered Mesoporous Carbon Nitride and Its Use as Electrochemical Sensing Platform for $\mathrm{H}_{2} \mathrm{O}_{2}$, Nitrobenzene, and NADH Detection. Biosens. Bioelectron. 2014, 53, 250-256. [CrossRef] [PubMed]

77. Liu, S.; Yu, B.; Fei, T.; Zhang, T. Low Temperature Thermal Treatment of Hexamethylenetetramine to Synthesize Nitrogen-Doped Carbon for Non-Enzymatic H2O2 Sensing. Sens. Actuators B 2014, 201, $240-245$. [CrossRef]

78. Pollack, B.; Holmberg, S.; George, D.; Tran, I.; Madou, M.; Ghazinejad, M. Nitrogen-Rich Polyacrylonitrile-Based Graphitic Carbons for Hydrogen Peroxide Sensing. Sensors 2017, 17, 2407. [CrossRef] [PubMed]

79. Otieno, B.A.; Krause, C.E.; Latus, A.; Chikkaveeraiah, B.V.; Faria, R.C.; Rusling, J.F. On-line Protein Capture on Magnetic Beads for Ultrasensitive Microfluidic Immunoassays of Cancer Biomarkers. Biosens. Bioelectron. 2014, 53, 268-274. [CrossRef] [PubMed]

80. Hayes, W.I.; Lubarsky, G.; Li, M.; Papakonstantinou, P. Mechanical Exfoliation of Graphite in 1-Butyl-Methylimidazolium Hexafluorophosphate $\left(\mathrm{BMIM}_{\mathrm{P}} \mathrm{PF}_{6}\right)$ Providing Graphene Nanoplatelets that Exhibit Enhanced Electrocatalysis. J. Power Sources 2014, 271, 312-325. [CrossRef]

81. Yang, X.; Haubold, L.; DeVivo, G.; Swain, G.M. Electroanalytical Performance of Nitrogen-Containing Tetrahedral Amorphous Carbon Thin-Film Electrodes. Anal. Chem. 2012, 84, 6240-6248. [CrossRef]

82. Kamata, T.; Kato, D.; Hirono, S.; Niwa, O. Structure and Electrochemical Performance of Nitrogen-Doped Carbon Film Formed by Electron Cyclotron Resonance Sputtering. Anal. Chem. 2013, 85, 9845-9851. [CrossRef] [PubMed]

83. Behan, J.A.; Stamatin, S.N.; Hoque, M.K.; Ciapetti, G.; Zen, F.; Esteban-Tejeda, L.; Colavita, P.E. Combined Optoelectronic and Electrochemical Study of Nitrogenated Carbon Electrodes. J. Phys. Chem. C 2017, 121, 6596-6604. [CrossRef]

84. Tian, J.; Liu, Q.; Ge, C.; Xing, Z.; Asiri, A.M.; Al-Youbi, A.O.; Sun, X. Ultrathin Graphitic Carbon Nitride Nanosheets: A Low-Cost, Green, and Highly Efficient Electrocatalyst Toward the Reduction of Hydrogen Peroxide and Its Glucose Biosensing Application. Nanoscale 2013, 5, 8921-8924. [CrossRef] [PubMed] 